\title{
AN INTRODUCTION TO EXPERIMENTAL AND CLINICAL STUDIES OF CARBOXYLIC CATION EXCHANGE RESINS
}

\author{
By T. S. DANOWSKI, L. GREENMAN, J. H. PETERS, AND F. M. MATEER \\ (From the Department of Research Medicine, University of Pittsburgh School of Medicine, \\ Pittsburgh, $P a$.)
}

(Submitted for publication April 23, 1951; accepted July 9, 1951)

Problems in the regulation of the composition and volume of body fluids in health and in disease states fall into three general groups which involve either $a$ ) maintenance of the status quo, assuming it is not far removed from normal, or $b$ ) replacement of depleted body stores of water, electrolytes, or colloids, or $c$ ) removal of constituents present in excess. Judicious prescription or interdiction of extracellular and cellular ions and water, based on a knowledge of external and internal exchanges, will often suffice in the first two categories (1-8). On the other hand even marked restriction of intake may not lower, for example, body sodium or potassium in the third group. In these instances limitation of intake will be effective only if negative external balances of sufficient magnitude are achieved by losses of these ions in urine, sweat, gastrointestinal secretions, or stools (9-13). In many clinical situations this can be accomplished with relative ease. Thus edema of varied etiology can be controlled or actually cleared through sodium and water diuresis during salt restriction (14-17). In other instances of congestive failure, cirrhosis, or renal disease with or without significant hypoalbuminemia this regimen proves ineffective, even when sodium ingestion has been reduced essentially to zero and even though simultaneous diuretic measures may be employed (1820). Similarly in renal disease, as in anuria, the kidney can no longer jettison excesses of ions such as potassium, sodium, or chloride (21-23).

Under such circumstances only a limited number of therapeutic procedures have been available prior to the introduction of cation exchange resins, all relatively complicated. The various dialyzers which can be used to remove electrolytes from blood require complex apparatus and constant attention (24-28). Also untoward reactions related either to cellophane or to inadequacies of the dialyzing fluid are not uncommon. The latter limitation is likewise present in the alternatives of intestinal or peritoneal lavage together with the additional disadvantage of relative inefficiency and, in the second of these two, the risk of uncontrollable infection (12, 29-32). Finally, the growing body of evidence that sodium restriction may be beneficial in certain vascular diseases (33) will extend to a wider segment of the population the burden of the unpalatability of the truly salt-free diet.

Preliminary studies with cation exchange resins indicate that these substances offer a new approach to the control and correction of excessive retention of cations in body fluids $(13,34-37)$. They can interfere with the absorption of sodium, potassium, and probably calcium and magnesium from the gastrointestinal tract. Furthermore, they may also remove endogenous stores of some of these ions * since under ordinary physiological circumstances relatively huge amounts of these body electrolytes are secreted into the gastrointestinal tract and subsequently reabsorbed (3). Once attached to the resin they may be excreted via stools, producing desired, or at times undesirable, negative balances. In the latter instance the problem is simple since, as indicated earlier, replacement of body constituents is possible.

One additional point should be made in view of the findings to be presented in subsequent papers of this study: the removal of positive ions by resins must inevitably be accompanied by a release of some other cation in equivalent amounts. It is obvious that if these particles are in turn absorbed they may of themselves produce distinct effects. The experimental findings to be presented in this series of studies substantiate this.

An understanding of the properties of the synthetic cation exchange resins in general and of the carboxylic type in particular will help in the interpretation and explanation of many of the biochemical effects which we have noted in our ex- 


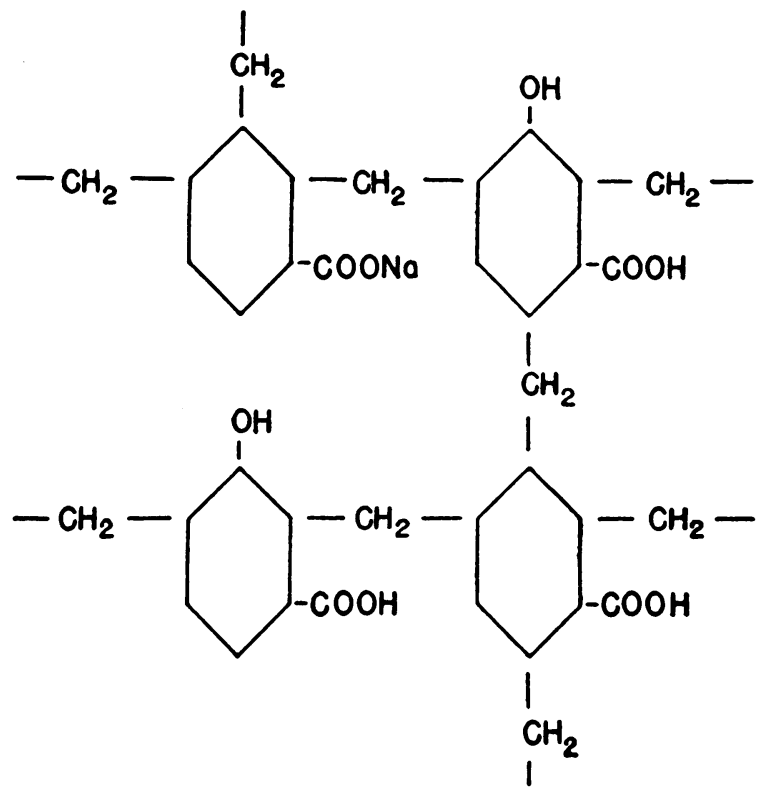

Fig. 1. Chemical Formula of a Synthetic Carboxylic Cation Exchanger

A schematic representation of a segment of a carboxylic cation exchange resin in the hydrogen form or cycle. One of its hydrogen ions has been replaced by sodium after exposure to a sodium chloride solution. Exchanger $-\mathrm{COOH}+\mathrm{NaCl} \longleftrightarrow$ Exchanger-COONA $+\mathrm{HCL}$. The $\mathrm{CH}_{2}$ groups unite the benzene rings of the polymer in chains and cross linkages which limit the swelling of the resin in aqueous or organic solvents. The degree of this swelling is governed by their frequency in the molecular unit.

perimental subjects. These agents are polymers of aromatic hydrocarbons such as phenolsulfonic acid or benzoic acid linked and cross linked by short, stable, and virtually indestructible carbon chains contributed by the condensing agent, usually formaldehyde (38-40) (Fig. 1). Chemical groups available for the cation exchange process, such as the sulfonic $\left(-\mathrm{SO}_{3} \mathrm{H}\right)$, carboxylic $(-\mathrm{COOH})$, or phenolic $(-\mathrm{OH})$, are attached to the benzene ring. In aqueous and other solutions these resins take in water or the particular organic solvent in which they may be suspended and increase in bulk. In this state they can properly be spoken of as gels. The swelling is attributable to the fact that the hydrogen ion or any other cation associated with the acid radical ionizes and exerts an osmotic pressure. The exchange resin when wet therefore has many of the properties of an acid or of a concentrated salt solution. In the transformation from the dry to the wet state water or other solvents penetrate the surface and enter the interstices of the resin structure until the osmotic pressure of the fluid inside the resin particle, together with the resistance exerted by the linkages and cross linkages, exactly equals the osmotic pressure on the outside $(41,42)$. Insofar as the distribution of electrolytes is concerned, equilibria are attained which are quite in keeping with the Gibbs-Donnan effect, at least in the more concentrated solutions. Hence anions common to both the gel and the circumambient solution will always be present in lower concentration in the resin, whereas the reverse will be true of the associated cations. It is obvious therefore that the exchange processes cannot be explained by simple adsorption.

The property which permits the exchange of one cation attached to a resin for another in its environment is fundamentally based upon the fact that resins have different degrees of affinity for the different cations. Thus the same exchanger under the same physical conditions exposed to a dilute solution containing identical concentrations of magnesium, calcium, and sodium will preferentially bind larger amounts of magnesium than of calcium, and more calcium than sodium. The characteristics of the cations themselves which are known to show a positive correlation with the affinity of the exchanger for a particular cation include valence, atomic weight, and the radius of the unhydrated ion. These orders of preference recur irrespective of the attending anions, with the proviso that they not be of the type which form complex salts $(38-42)$. The hierarchy of affinities evident in dilute solutions is readily upset, however, by increases in the concentration of one of the competing cations, by alterations in the $\mathrm{pH}$ of the solution, by replacement of water with other solvents, and, finally, by increased swelling of the resin (43).

The carboxylic cation exchangers employed in our studies in general share with the sulfonic and phenolic resins all of the above-described features. In their acid properties, however, the carboxylic resins differ from the other two types of resin, occupying an intermediate position. Thus with $\mathrm{pH}$ values greater than 3.5, replacement of the carboxylic group hydrogen by other cations occurs to a progressively greater extent and ultimately reaches a maximum. The sulfonic resins on the 
other hand are strongly acidic and can function maximally at any $\mathrm{pH}$ value; the phenolic exchangers are weakly acidic, ionize only to a slight degree and remain relatively inert until $\mathrm{pH}$ values high in the alkaline range are attained. It is obvious that of these three groups of agents the $\mathrm{pH}$ range over which the carboxylic resin functions as an exchanger and its relatively weak acidic properties which can be readily buffered in body fluids render it most suitable for biological administration. Further theoretical advantages of the carboxylic resins over the sulfonic acid derivatives include the fact that the latter have a lower exchange capacity and that they may produce abrupt changes in local and systemic acid-base balances (38-44).

As the lower $\mathrm{pH}$ ranges are approached the greater affinity of the carboxylic cation exchangers for the hydrogen ion becomes more and more manifest and other cations are progressively displaced until at $\mathrm{pH}$ values of 3.5 or less the exchanger reverts entirely to the hydrogen form. It is probable that irrespective of the form or cycle in which the resin is given, it is converted in the stomach to the hydrogen form. Therefore, the net effect of giving the sodium derivative of the resin is that of administering a cation with an unabsorbable anion.

The studies to be presented reveal a relatively low in vivo capacity of this particular resin for sodium and potassium compared to those demonstrable at similar $\mathrm{pH}$ values in vitro. This should not be surprising since it is obvious that other cations, particularly calcium, magnesium, iron, and organic cations, can preferentially assume positions in the resin. Furthermore, interference of organic substances such as lipids, steroids, and proteins with the exchange process has not been defined.

The arrangement and sequence of this and of the papers which follow arose from a combination of necessity and predetermined plan. The studies in animals using large per kilogram dosage preceded the administration of these agents to human subjects. . The second paper, therefore, describes serum, urine, stool and balance findings during the administration to dogs of a carboxylic cation exchanger in one of two cycles or forms (45). Human studies in which resins were ingested in a variety of cycles make up the third paper (46). In these investigations sodium usually was not markedly restricted; control stool data were obtained from a large group of subjects maintained on either whole milk, a diabetic diet, a regular diet or a so-called "salt-free" regular diet. These data are presented in the tables and figures of the papers which follow; when necessary, they have been supplemented by acceptable control material. In the fourth paper, attributes of the individual cycles of the resin evident in the preceding paper have been measured during the simultaneous administration of two or more of the polymers in varying proportions, and employed in attempts to cancel certain toxic effects of ACTH and cortisone (47). The results have been evaluated against the control background described in the preceding paper. The possible influences of the steroids and of the trophic hormone or hormones of the adrenal on stool composition have been defined elsewhere (48). The fifth unit reports the events which occur in nephrotic children to whom an acidifying exchanger is administered during the course of essentially complete sodium restriction (49). In the sixth and final paper attempts are made to summarize and interconnect the findings of all the studies, to list logical sequellar investigations, and to predict the probable clinical utilities of the resins (50).

A word about the cooperative character of these studies is in order. Examination of the tabulated material in the papers which follow will reveal that the bulk of the work embodied in this collection is based on a substantial number of balance periods in dogs and in patients. These data were gathered in a period of 16 months, and their collection and completion would have been quite impossible without the active and time-consuming cooperation of many others besides the individuals appearing as co-authors. The people and organizations who have generously given time, effort, and frequently funds to support this investigation are listed in the following section. A special mention should be made, however, of the contribution of the patients themselves who not only cooperated, but often participated actively in assisting us to assure complete and accurate collections.

\section{ACKNOWLEDGMENTS}

The contributions of the following individuals and organizations are gratefully acknowledged: 
a) Dr. Gustav Martin and the National Drug Company of Philadelphia furnished all of the resins under the designation "Natrinil," milk protein supplements such as "Protinal" for the preparation of formulae, as well as funds for partial support of the project.

b) Mead Johnson and Company contributed a portion of the "Lonalac" employed in the preparation of sodiumfree formulae.

c) The Borden Company furnished most of the $\beta$-lactose used as a carbohydrate supplement in the formulae.

d) The investigations were supported in part by research grants from the National Institutes of Health, Public Health Service (ACTH and Cortisone studies).

e) The Western Pennsylvania Chapter of the American Rheumatism Association provided us with a generous grant-in-aid.

f) The Silver Fund of the University of Pittsburgh under the direction of Dr. Paul B. Steele allotted steroids for therapy of certain arthritic patients.

$g$ ) The Addison H. Gibson Foundation provided medications for a number of the patients included in this study.

h) The Rheumatic Fever Heart Disease Fund of the Kiwanis Club of Pittsburgh, through the collaboration of Dr. Frank J. Gregg, has given us substantial help in obtaining cortisone, ACTH, and technical assistance.

Cooperating personnel to whom grateful acknowledgment is made for assistance and advice:

Professional: Drs. Alexander H. Colwell and E. R. McCluskey and their staffs in the Children's and Presbyterian Hospitals.

Nursing care: The Misses Jacqueline Kruman, Mildred Merkel, and Rosemary O'Connor, Renziehausen Ward and Clinic, Children's Hospital of Pittsburgh; Mrs. Margaretta Grace and staff, Children's Hospital Clinical Ward; and Miss Dorothy Hoehl and staff, Presbyterian Hospital.

Animal facilities: Dr. Campbell Moses and the staff of the Addison Gibson Laboratory of the University of Pittsburgh School of Medicine.

Technical staff: The following have participated at one time or another: Misses Margaret Dodge, Mary Johns, Dorothy King, Margot Leinberger, Patricia Leix, Phyllis Linder, Agnes Rovnanek, Mary Saphos, Julia Skwarko, Harriet Treleesky, Mary Lou Wilson, and Joan Woolard; Mrs. Dorothy Burke, Mrs. Elizabeth Chase, and Mrs. Mercine Nefores.

Volunteer assistants: William Bradshaw, James Finlay, Louis Neft, Edward Seitz, and Robert Schneider.

Statistical services: Mr. Carrol Weil, Mellon Institute, Pittsburgh, $\mathrm{Pa}$.

Special services and adult dietary formula preparation: Mr. George C. Hill.

Children's diets and formulae: Misses Gwendolyn Fulmer and Norma Poster.

Photographs and illustrations: The tables and many of the figures and charts were photographed and/or drawn by Mr. Alex Varlashkin.

Secretarial assistance: Miss A. D. Francis prepared most of the manuscripts and tables and some of the il- lustrations. Mrs. Josephine Easler and Miss A. E. Gilcher assisted with the manuscripts and the bibliographies.

\section{REFERENCES}

1. Kerpel-Fronius, E., Salzmangelzustände und chloroprive Azotämie. Ergebn. d. inn. Med. u. Kinderh., 1936, 51, 623.

2. McCance, R. A., Experimental sodium chloride deficiency in man. Proc. Roy. Soc., London, 1936, 119B, 245.

3. Gamble, J. L., Chemical Anatomy; Physiology and Pathology of Extracellular Fluid. Harvard University Press, Cambridge, Mass., 1950.

4. Peters, J. P., Water balance in health and disease, in Diseases of Metabolism, edited by Duncan, G. G. W. B. Saunders Company, Philadelphia, 1947, pp. 271-346.

5. Peters, J. P., The regulation of the volume and composition of body fluids. J. Missouri Med. A., 1950, $47,9$.

6. Shohl, A. T., Mineral Metabolism. Reinhold Publishing Co., New York, 1939.

7. Darrow, D. C., Body-fluid physiology : the relation of tissue composition to problems of water and electrolyte balance. New England J. Med., 1945, 233, 91.

8. Butler, A. M., Parenteral fluid therapy in diabetic coma. Acta pediat., 1949, 38, 59.

9. Keith, N. M., Barrier, C. W., and Whelan, M., The diuretic action of ammonium chloride and Novasurol, in cases of nephritis with edema. J. A. M. A., 1925, 85, 799.

10. Blumgart, H. L., Gilligan, D. R., Levy, R. C., Brown, M. G., and Volk, M. C., Action of diuretic drugs. I. Action of diuretics in normal persons. Arch. Int. Med., 1934, 54, 40.

11. Keutmann, E. H., Bassett, S. H., and Warren, S. L., Electrolyte balances during artificial fever with special reference to loss through the skin. J. Clin. Invest., 1939, 18, 239.

12. Maluf, N. S. R., Intestinal and gastric perfusion in a patient with severe chronic uremia. J. Urol., 1950, 64, 268.

13. Dock, W., Sodium depletion as a therapeutic procedure: the value of ion exchange resins in withdrawing sodium from the body. Tr. A. Am. Physicians, 1946, 59, 282.

14. Schroeder, H. A., Studies on congestive heart failure. I. The importance of the restriction of salt as compared to water. Am. Heart J., 1941, 22, 141.

15. Schemm, F. R., Certain clinical aspects of the application of water balance principles to heart and kidney disease. Ann. Int. Med., 1949, 30, 92.

16. Bridges, W. C., Wheeler, E. O., and White, P. D., Low-sodium diet and free fluid intake in the treatment of congestive heart failure, preliminary report. New England J. Med., 1946, 234, 573.

17. Gorham, L. W., Lester, D. E., Wolf, A. V., and Shultz, H. H., The relative importance of dietary 
sodium chloride and water intake in cardiac edema. Ann. Int. Med., 1947, 27, 575.

18. Janeway, C. A., Moll, G. H., Hallman, N., Barness, L. A., and Metcoff, J., Management of the nephrotic syndrome in children. Bull. N. England Med. Center, 1949, 11, 5.

19. Faloon, W. W., Eckhardt, R. D., Cooper, A. M., and Davidson, C. S., The effect of human serum albumin, mercurial diuretics, and a low sodium diet on sodium excretion in patients with cirrhosis of the liver. J. Clin. Invest., 1949, 28, 595.

20. Proger, S., and O'Connor, J. J., Intractable heart failure. Ann. Int. Med., 1950, 33, 1349.

21. Borst, J. G. G., Protein catabolism in uraemia; effects of protein-free diet, infections, and blood transfusions. Lancet, 1948, 1, 824.

22. Strauss, M. B., Acute renal insufficiency due to lowernephron nephrosis. New England J. Med., 1948, 239, 693.

23. Bull, G. M., Joekes, A. M., and Lowe, K. G., Conservative treatment of anuric uremia. Lancet, 1949, 2, 229.

24. Kolff, W. J., New Ways of Treating Uraemia. The Artificial Kidney, Peritoneal Lavage, Intestinal Lavage. J. \& A. Churchill, Ltd., London, 1947.

25. Alwall, N., On the artificial kidney. VIII-XIII. Acta med. Scandinav., 1949, 133, Suppl. 229.

26. Murray, G., Artificial kidney. J. A. M. A., 1948, 137, 1596.

27. Vanatta, J., Muirhead, E. E., and Grollman, A., Improvements on the artificial kidney: an experimental study of its application to dogs bilaterally nephrectomized or otherwise deprived of renal function. Am. J. Physiol., 1949, 156, 443.

28. Muirhead, E. E., Vanatta, J., and Grollman, A., Acute renal insufficiency. A comparison of the use of an artificial kidney, peritoneal lavage and more conservative methods in its management. Arch. Int. Med., 1949, 83, 528.

29. Hicks, M. H., Crutchfield, A. J., and Wood, J. E., Jr., Intestinal lavage in the potassium intoxication of lower nephron nephrosis. Am. J. Med., 1950, 9, 57.

30. Bernstein, L., O'Neill, P. B., Bernstein, A., and Hoffman, W. S., Pergastric intestinal perfusion for uremia. J. Lab. \& Clin. Med., 1950, 36, 849.

31. Fine, J., Frank, H. A., and Seligman, A. M., Treatment of acute renal failure by peritoneal irrigation. Ann. Surg., 1946, 124, 857.

32. Odell, H. M., Ferris, D. O., and Power, M. H., Clinical considerations of the problem of extrarenal excretion; peritoneal lavage. M. Clin. N. America, 1948, 32, 989.

33. Watkin, D. M., Froeb, H. F., Hatch, F. T., and Gutman, A. B., Effects of diet in essential hypertension. I. Baseline study : effects in 86 cases of prolonged hospitalization on regular hospital diet. Am. J. Med., 1950, 9, 428.
34. Dock, W., Use of sodium depletion in therapy, in Advances in Internal Medicine, edited by Dock, W., and Snapper, I. Year Book Publishers, Chicago, Ill., 1950, Vol. 4, p: 273.

35. Irwin, L., Berger, E. Y., Rosenberg, B., and Jackenthal, $R$., The effect of a cation exchange resin on electrolyte balance and its use in edematous states. J. Clin. Invest., 1949, 28, 1403.

36. Danowski, T. S., Greenman, L., Mateer, F., Peters, J. H., Weigand, F. A., Mermelstein, H. E., and Clarke, C. E., Carboxylic cation exchange resin studies in animals and humans. J. Clin. Invest., 1950, 29, 807.

37. Hay, S. H., and Wood, J. E., Jr., Cation exchange resins in the treatment of congestive heart failure. Ann. Int. Med., 1950, 33, 1139.

38. Boyd, G. E., Schubert, J., and Adamson, A. W., The exchange adsorption of ions from aqueous solutions by organic zeolites. I. Ion-exchange equilibria. J. Am. Chem. Soc., 1947, 69, 2818.

39. Bauman, W. C., and Eichhorn, J., Fundamental properties of a synthetic cation exchange resin. J. Am. Chem. Soc., 1947, 69, 2830.

40. Kunin, R., Ion exchange. Anal. Chem., 1949, $21,87$.

41. Nachod, F. C., Ion Exchange: Theory and Application. Academic Press, Inc., New York, 1949.

42. Kunin, R., and Myers, R. J., Ion Exchange Resins. John Wiley \& Sons, Inc., New York, 1950.

43. Winters, J. C., Rohm \& Haas Company, Philadelphia, Pa., Personal communication.

44. Dock, W., and Frank, N. R., Cation exchangers : their use and hazards as aids in managing edema. Am. Heart J., 1950, 40, 638.

45. Danowski, T. S., Greenman, L., Mateer, F. M., Parsons, W. B., Weigand, F. A., Mermelstein, H., and Peters, J. H., Carboxylic cation exchange resin effects in dogs. J. Clin. Invest., 1951, 30, 984.

46. Greenman, L., Peters, J. H., Mateer, F. M., Weigand, F. A., Wilkins, D., Tarail, R., Rhodes, G., and Danowski, T. S., Biochemical changes accompanying the ingestion of a carboxylic cation exchanger in the hydrogen, ammonium, sodium, potassium, or calcium form. J. Clin. Invest., 1951, 30, 995.

47. Peters, J. H., Danowski, T. S., Greenman, L., Weigand, F. A., Clarke, C. E., Garver, K., Mateer, F. M., and Tarail, R., Acidifying and non-acidifying carboxylic resin mixtures used alone and with ACTH or cortisone. J. Clin. Invest., 1951, 30, 1009.

48. Danowski, T. S., Greenman, L., Peters, J. H., Mateer, F. M., and Weigand, F. A., Unpublished data.

49. Mateer, F. M., Erhard, L. H., Price, M., Weigand, F. A., Peters, J. H., Danowski, T. S., Tarail, R., and Greenman, L., Sodium restriction and cation exchange resin therapy in nephrotic children. J. Clin. Invest., 1951, 30, 1018.

50. Greenman, L., Peters, J. H., Mateer, F. M., and Danowski, T. S., Probable clinical utility of cation exchange resins. J. Clin. Invest., 1951, 30, 1027. 